\title{
Using improved iterative gravity method to optimize the investment location of agricultural biomass power generation projects: a case study
}

Biomass power generation has characteristics of good quality of power generation, high reliability and mature technology. It plays significant aspects in maintaining the safety of energy, optimizing energy structure, alleviating environmental pollution and promoting the economic development in the rural areas. Analyzing the investment of biomass power generation in China systematically cannot only improve the scientificity of the investment process, but also guide the industry to develop rapidly and healthily. At present, the investment areas of agricultural biomass power generation projects are too concentrated and the fuel supply is difficult, which affect the normal operation of biomass power plants and lead to loss or on the verge of profit and loss of biomass power generation plants. This paper constructed the optimal model of investment location of agricultural biomass power generation projects using the iterative gravity algorithm based on the key factors analysis to affect the operation costs of agricultural biomass power plants. The model optimized the transportation lines and transportation distance, and gained the smallest transport costs of power generation materials after a few iterative calculations. This paper took Huantai County as an example, and determined the optimal investment location of agricultural biomass power project using the Region props toolbox of Matlab 7.4. The simulating calculation of Huantai County showed that the results given by this model are reliable, and this method to select the investment location of agricultural biomass power projects is feasible and effective.

Keywords: Agricultural biomass power generation projects, investment location selection, optimized iterative gravity method, Huantai County.

\section{Introduction}

A t present, energy shortage and environmental pollution has become the focus of common concern around the world, which is also an important problem

Messrs. Zhibin Liu, Xin Wang, Department of Economics and Management, North China Electric Power University, Baoding, and Aisheng Ren, Institute of Agricultural Economics and Development, Chinese Academy of Agricultural Sciences, Beijing, China. must be faced of social and economic development in China. Biomass power generation is to generate power taking the biomass resources as raw materials, as a form of renewable energy power generation; biomass power generation technology is relatively mature, the power quality is good and reliability of the power generation is higher. Biomass power generation can be done without intermittent compared to the form of wind power and solar power. And biomass resource is abundant in China, more than 700 million tonnes of crop straw can be produced each year [1-5]. It is an effective way of making full use of biomass resources, alleviating environment pollution and increasing farmers' income to develop the biomass power generation.

Since 2005, the "Renewable Energy Law" and a series of supporting policies have been promulgated and implemented in succession, which promoted the rapid development of biomass power generation industry greatly. In some regions, resource reserves, climate environment and electric power market demand conditions are better, and many investors invested in the regions, which led to the locations of biomass power generation projects are too concentrated, the distance of biomass power generation projects is too close. Within a radius of $200 \mathrm{~km}$ in the north of Jiangsu province, a dozen biomass power generation plants were constructed, which cause the fuel resources shortage of biomass power generation inevitably, influence the normal operation of biomass power plants, lead the biomass power generation plants to loss or on the verge of profit and loss. Therefore, the government should take effective measures to regulate the investment layout of biomass power generation projects [6-11].

Different investment locations are related to the construction investment costs of biomass power generation projects, the amount of available biomass fuels and the operating costs after the completion of biomass power plants. The gap of investment costs of biomass power generation projects in the same city or county is not large. The different profit levels mainly depend on the operating costs of biomass power generation plants. The generating costs of agricultural biomass power generation plants mainly include: biomass fuel costs, purchased power costs, water expenses, material 
expenses, wage expenses, depreciation expenses, repairing expenses, administrative expenses and financial expenses. We gained the generating cost composition (Fig.1) based on the field research data of the agricultural biomass power plants have been put into operation. It can be found that the agricultural biomass costs account for more that $60 \%$ of total power generation costs.

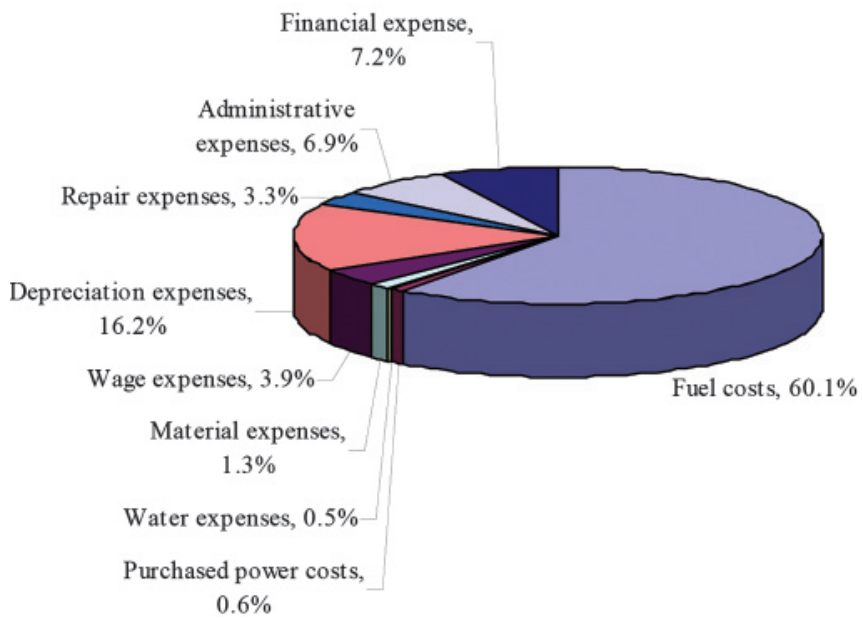

Fig.1 Power generation costs of the agricultural biomass power generation plants

The fuel costs of agricultural biomass power plants mainly include: purchase costs, processing costs, transportation costs, storage costs and wastage costs. The fuel costs composition is as shown in Fig.2, the fuel purchase costs account for $60 \%$ nearly of total fuel costs.

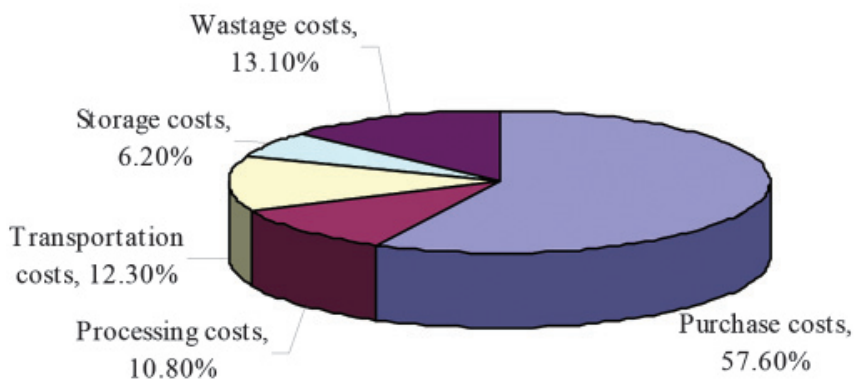

Fig.2 Fuel costs of the agricultural biomass power generation plants

The processing costs, storage costs and wastage costs are fixed in biomass fuel costs, the fuel purchase costs and transportation costs account for $69.9 \%$ of total fuel costs, account for $42.0 \%$ of total operation costs. The two costs can be reduced through the investment location selection of agricultural biomass power plants. The investment location selection of agricultural biomass power plants is systematic process, and a scientific and quantitative argumentation. There are many methods that have been widely applied to select the investment location, such as: analytic hierarchy process method, fuzzy evaluating method, etc. However, these methods are subject to stochastic factors in the calculation process, and the results are influenced by subjective experience and knowledge limitations easily, which often with personal bias and one-sidedness. The gravity method can overcome the influence of subjective factors and has been applied widely. This paper will use the improved iterative gravity method to determine the optimal investment location of agricultural biomass power generation projects.

\section{Methodology}

\subsection{THE BASIC PRINCIPLE OF GRAVITY METHOD}

Gravity method is to determine the investment location through simulating the object gravity, and which is based on the principles of total minimum transportation cost [12-18]. We suppose the $\mathrm{m}$ distribution locations in different coordinate point $\left(\mathrm{u}_{1}, \mathrm{v}_{1}\right)$. If the distribution center location is in coordinate point $\left(\mathrm{u}_{0}, \mathrm{v}_{0}\right)$, the total transportation cost $\mathrm{S}$ can be expressed as follows:

$$
S=\sum_{l=1}^{m} T_{l} W_{l} C_{l}
$$

In formula (1), $T_{l}$ denotes the transport costs from distribution center to distribution location $l, W_{l}$ denotes the demands of distribution location $l, C_{l}$ denotes the distance from demand location $l$ to distribution center.

The distance $C_{l}$ can be expressed as follows:

$$
C_{l}=\sqrt{\left(u_{l}-u_{0}\right)^{2}+\left(v_{l}-v_{0}\right)^{2}}
$$

According to the gravity method, each distribution location has quality, the $r_{l}$ expresses the equivalent weight of each particle, and the gravity center is the spot that the distance is shortest to the particles.

Thus, the logistics distribution center location is transferred to solve the bar centric coordinates.

We suppose,

$r_{l}=T_{l} W_{l}$

We define the equivalent weight of each particle is $\mathrm{R}$, then

$$
\sum_{l=1}^{m} T_{l} W_{l} C_{l}=\sum_{l=1}^{m} r_{l} C_{l}
$$

Because of the geometry characteristics of the gravity center, the moment produced in UOV plane of equivalent weight in gravity center relative to the origin used to express as the following physical equation:

$$
R C_{0}=\sum_{l=1}^{m} r_{l} C_{l}=\sum_{l=1}^{m} T_{l} W_{l} C_{l}
$$

We decompose the moment along the axis $\mathrm{U}$ and $\mathrm{V}$ :

$$
\left\{\begin{array}{l}
R u_{0}=\sum_{l=1}^{m} r_{l} u_{l}=\sum_{l=1}^{m} T_{l} W_{l} u_{l} \\
R v_{0}=\sum_{l=1}^{m} r_{l} v_{l}=\sum_{l=1}^{m} T_{l} W_{l} v_{l}
\end{array}\right.
$$

We input the formula (2) to formula (1), and got the 
formula (6) through took partial derivative:

$$
\left\{\begin{array}{l}
\frac{\partial S}{\partial u_{0}}=\sum_{l=1}^{m} T_{l} W_{l}\left(u_{0}-u_{l}\right) c_{l}=0 \\
\frac{\partial S}{\partial v_{0}}=\sum_{l=1}^{m} T_{l} W_{l}\left(v_{0}-v_{l}\right) c_{l}=0
\end{array}\right.
$$

Then we obtaine the most suitable $\mathrm{u}_{0}$ and $\mathrm{v}_{0}$, namely

$$
\left\{\begin{array}{c}
u_{0}=\frac{\sum_{l=1}^{m} T_{l} W_{l} u_{l} / c_{l}}{\sum_{l=1}^{m} T_{l} W_{l} / c_{l}} \\
v_{0}=\frac{\sum_{l=1}^{m} T_{l} W_{l} v_{l} / c_{l}}{\sum_{l=1}^{m} T_{l} W_{l} / c_{l}}
\end{array}\right.
$$

2.2 OptIMAL SELECTION MODEL CONSTRUCTION BASED ON ITERATIVE GRAVITY METHOD

Iterative gravity method is also called differential method, which is proposed to overcome the shortcomings of gravity method. This method takes the result of gravity method as initial solution, and gets the exact solution by iteration [1926]. This paper adopted the geometric center of agricultural biomass resource region to represent the entire region. We suppose then geometric centers of agricultural biomass resource regions to distribute in different coordinate points $\left(x_{i}, y_{i}\right)$, and solve the initial solution $\left(x_{0}, y_{0}\right)$ using gravity method. The computation formula is as follows:

$$
\left\{\begin{array}{l}
x_{0}=\frac{\sum_{i=1}^{n}\left(a_{i} w_{i} x_{i}\right)}{\sum_{i=1}^{n}\left(a_{i} w_{i}\right)} \\
y_{0}=\frac{\sum_{i=1}^{n}\left(a_{i} w_{i} y_{i}\right)}{\sum_{i=1}^{n}\left(a_{i} w_{i}\right)}
\end{array}\right.
$$

The total transportation costs can be expressed as:

$$
C_{0}=\sum_{i=1}^{n}\left(a_{i} w_{i} d_{i}\right)
$$

In formula (9), $a_{i}$ denotes the unit transportation costs from power generation plants to agricultural biomass resource region $i, w_{i}$ denotes the resource transportation volumes from power generation plants to agricultural biomass resource region $i, d$ denotes the straight line distance from power generation plants to agricultural biomass resource region $i$.

$$
d_{i}=\sqrt{\left(x_{0}-x_{i}\right)^{2}+\left(y_{0}-y_{i}\right)^{2}}
$$

The investment location selection should guarantee the lowest total transportation costs, and we suppose the $C_{0}$ is minimum:

$$
\left\{\begin{array}{l}
\frac{\partial C_{0}}{\partial x_{0}}=\sum \frac{a_{i} w_{i}\left(x_{0}-x_{i}\right)}{d_{i}}=0 \\
\frac{\partial C_{0}}{\partial y_{0}}=\sum \frac{a_{i} w_{i}\left(y_{0}-y_{i}\right)}{d_{i}}=0
\end{array}\right.
$$

We can gain the $\left(x_{0}^{*}, y_{0}^{*}\right)$, which is the iterative gravity solution:

$$
\left\{\begin{array}{l}
x_{0}^{*}=\frac{\sum_{i=1}^{n} a_{i} w_{i} x_{i} / d_{i}}{\sum_{i=1}^{n} a_{i} w_{i} / d_{i}} \\
y_{0}^{*}=\frac{\sum_{i=1}^{n} a_{i} w_{i} y_{i} / d_{i}}{\sum_{i=1}^{n} a_{i} w_{i} / d_{i}}
\end{array}\right.
$$

We input $\left(x_{0}^{*}, y_{0}{ }_{0}\right)$ to formula (8), gained the $C_{0}^{*}$ after the iteration, and compared to the original solutions $C_{0}$. If $C_{0}^{*}<C_{0}$, then we continued to iterate; If $C_{0}^{*}=C_{0}$, then we ended the operation, and the at this time is the optimal solution.

\section{Results and discussions}

Huantai county belongs to the Zibo City of Shandong province, which is located in the combination of mountainous area in the middle of Shandong and plains in the north of Shandong. Huantai county is the important commodity grain production base in China. Huantai county has 11 towns, the total area is $509 \mathrm{~km}^{2}$, and the total planting area of crops is $49600 \mathrm{hm}^{2}$. In order to alleviate the environmental pollution brought by straw burning, increases the farmers' income and develop the rural economy, Huantai county proposed to develop the agricultural biomass power generation projects. The administrative division and straw resource yield distribution of Huantai county is shown in Fig.3.

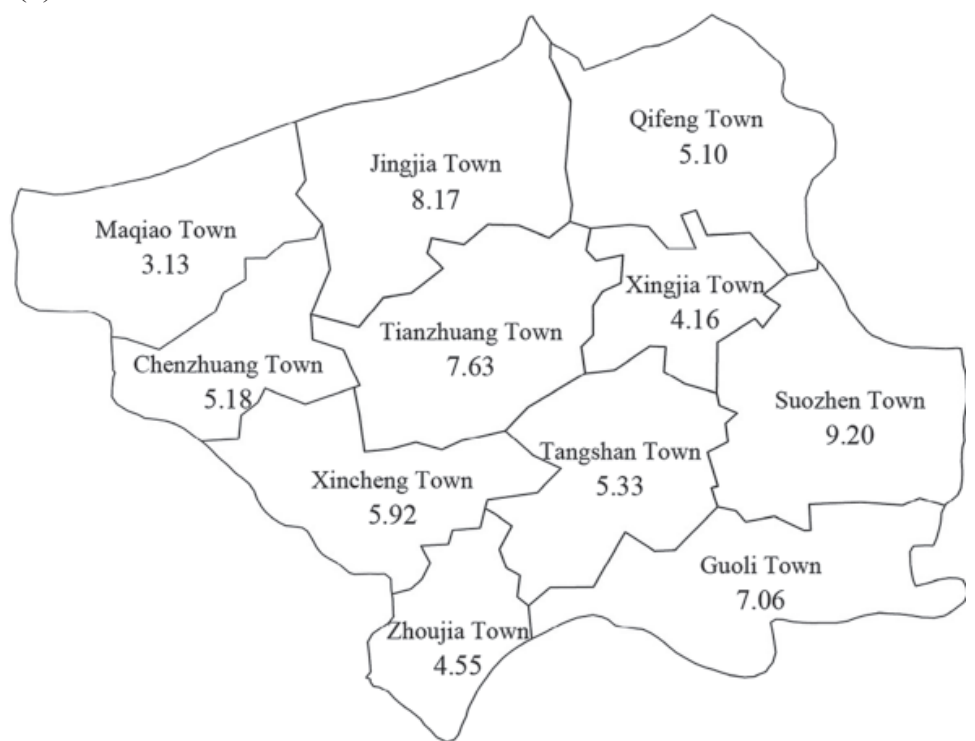

Fig.3 Administrative division and straw resource yield distribution of Huantai county 


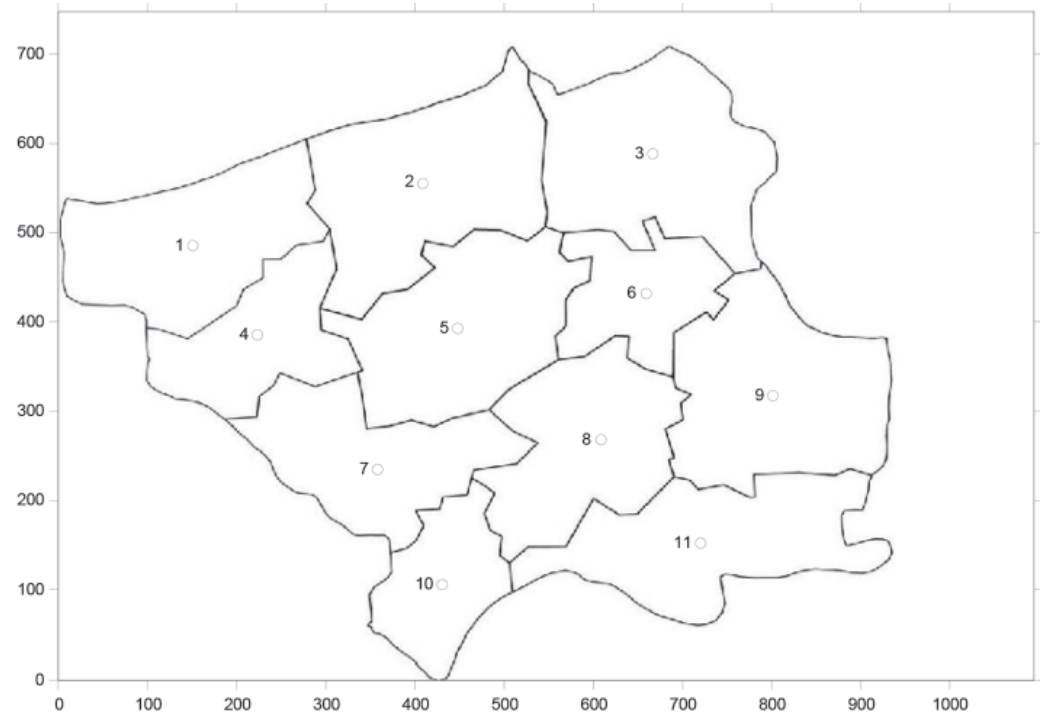

Fig.4 Geometric center locations of the towns in Huantai county

We used the image processing function Region props in the software toolbox Matlab 7.4 to process the image of Fig.3, and we gained the geometric center of the townships in Huantai county. The geometric center locations of the towns in Huantai county are shown in Fig.4, and the geometric center coordinates and straw resource yield of the towns in Huantai county is shown in Table 1.

We suppose that the straw resource purchase price and the freight in unit distance are equal, then we can gain the total minimum transportation cost of the agricultural biomass power generation plants is 15070.43 after 13 times of iteration computation, the optimal investment location coordinate is $(508.55,362.20)$. The iteration process is shown in Table 2.

Through iterative calculation, we could get the optimal investment location (the red point) of

TABLE 1: GEOMETRIC CENTER COORDINATES AND STRAW RESOURCE YIELD OF THE TOWNS IN HUANTAI COUNTY

\begin{tabular}{clccc}
\hline Number & Towns & $x_{i}$ & $y_{i}$ & $\begin{array}{c}\text { Straw yield } \\
\left(10^{4} \text { tonnes }\right)\end{array}$ \\
\hline 1 & Maqiao Town & 151 & 486 & 3.13 \\
2 & Jingjia Town & 408 & 556 & 8.17 \\
3 & Qifeng Town & 666 & 589 & 5.10 \\
4 & Chenzhuang Town & 223 & 386 & 5.18 \\
5 & Tianzhuang Town & 448 & 393 & 7.63 \\
6 & Xingjia Town & 659 & 432 & 4.16 \\
7 & Xincheng Town & 358 & 235 & 5.92 \\
8 & Tangshan Town & 608 & 269 & 5.33 \\
9 & Suozhen Town & 801 & 318 & 9.20 \\
10 & Zhoujia Town & 430 & 106 & 4.55 \\
11 & Guoli Town & 720 & 153 & 7.06 \\
\hline
\end{tabular}

TABLE 2: ITERATIVE PROCESS AND OPERATION RESULTS OF THE INVESTMENT LOCATION SELECTION OF THE AGRICULTURAL BIOMASS POWER GENERATION PROJECTS

\begin{tabular}{cccc}
\hline Iterative times & $\mathrm{X}$ & $\mathrm{Y}$ & $\mathrm{C}$ \\
\hline 0 & 522.99 & 354.57 & 15084.14 \\
1 & 518.88 & 357.08 & 15077.32 \\
2 & 515.90 & 358.65 & 15073.94 \\
3 & 513.77 & 359.70 & 15072.24 \\
4 & 512.25 & 360.44 & 15071.36 \\
5 & 511.15 & 360.96 & 15070.91 \\
6 & 510.37 & 361.33 & 15070.68 \\
7 & 509.80 & 361.60 & 15070.56 \\
8 & 509.40 & 361.79 & 15070.50 \\
9 & 509.10 & 361.93 & 15070.47 \\
10 & 508.89 & 362.03 & 15070.45 \\
11 & 508.74 & 362.10 & 15070.44 \\
12 & 508.63 & 362.16 & 15070.43 \\
13 & 508.55 & 362.20 & 15070.43 \\
\hline
\end{tabular}

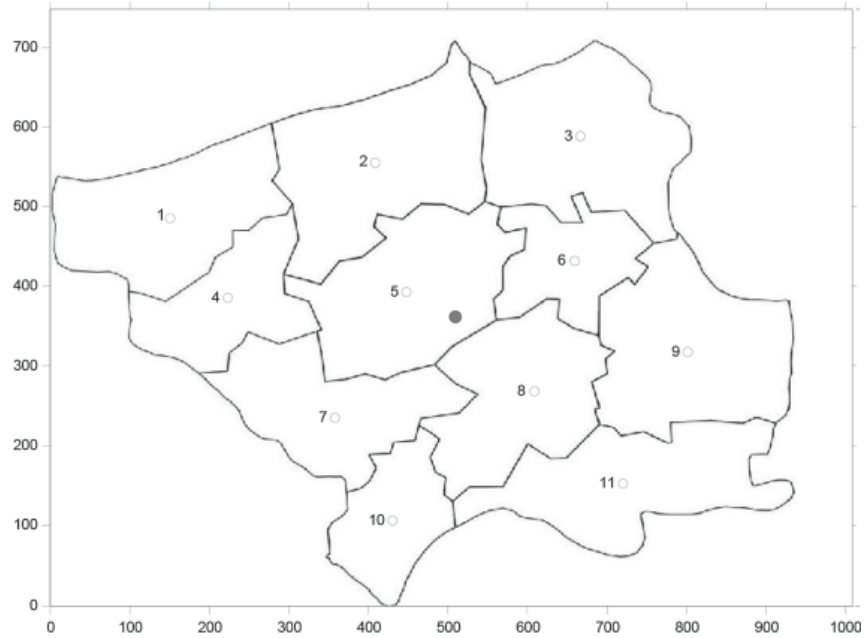

Fig.5 Optimal location of the agricultural biomass power generation project in Huantai county

agricultural biomass power generation projects in line with minimum transportation costs in Huantai county, which is as shown in Fig.5. The location is located in the outskirts of Huantai county, neither took up the urban construction lands, nor closed to main city supply networks, the line construction costs and infrastructure construction costs are low and the power plant staffing is more convenient, so it can be finalized for actual investment location.

\section{Conclusions}

The investment location selection of agricultural biomass power generation projects is associated with many factors, it needs large number of statistical calculations, and the factitious factors can be mixed into easily, which make the location selection work is difficult. On the basis of analyzing the important factors to affect the location selection of agricultural biomass power generation projects, we establish an optimal 
model of investment location using the iterative gravity method and determin the optimal investment location of agricultural biomass power generation plants using the image processing function Region props through considering the number of biomass resources, fuel purchase costs, transportation costs and other key indexes. The simulation test results show that the iterative gravity method can simulate experts carrying out the optimal selection of investment location of agricultural biomass power generation projects.

\section{Conflicts of interest}

We declare that there is no conflict of interest regarding the publication of this article.

\section{Acknowledgements}

This work is supported by "the Fundamental Research Funds for the Central Universities (2017MS199)" and "the Social Science Fund Projects in Hebei Province”.

\section{References}

[1] Zhang, M. M., Zhou, D. Q., Ding, H. and Jin, J. L. (2016): "Biomass Power Generation Investment in hina: A Real Options Evaluation", Sustainability, no. 8, p.1-22

[2] Zhao, Z. Y., Zuo, J., Wu, P. H., Yan, H. and Zillante, George (2016): "Competitiveness assessment of the biomass power generation industry in China: A five forces model study", Renewable Energy, vol. 89, p.144-153

[3] Lin, B. Q. and He, J. X.(2016): "Learning curves for harnessing biomass power: What could explain the reduction of its cost during the expansion of China?", Renewable Energy, vol. 89, p280-288

[4] Yan, Q. Y., Wan, W., Yuan, J. Y. Yin, J. T., Bale•entis, Tomas and Streimikiene, Dalia (2017): "Economic and technical efficiency of the biomass industry in China: A network data envelopment analysis model involving externalities", Energies, no. 10, p1-19

[5] Zhang, Y. Z., Zhao, X.G., Ren, L. Z., Liang, J. and Liu, P. K.(2017): "The development of China's biomass power industry under feed-in tariff and renewable portfolio standard: A system dynamics analysis", Energy, vol. 139, p947-961

[6] Abdelhady, Suzan, Borello, Domenico and Shaban, Ahmed (2018): "Techno-economic assessment of biomass power plant fed with rice straw: Sensitivity and parametric analysis of the performance and the LCOE", Renewable Energy, vol. 115, p1026-1034

[7] Zhao, Z. Y. and Yan, H. (2012): "Assessment of the biomass power generation industry in China", Renewable Energy, vol. 37, p53-60

[8] Chen, L.Q. (2012): "The broad prospects of biomass energy and its power generation industry", China New Energy, vol. 9, p53-55

[9] Cui, H.R. and Wu, R. M. (2012): "Feasibility analysis of biomass power generation in China", Energy Procedia, vol. 16, p45-52
[10] Lin, B. Q. and He, J. X. (2017): "Is biomass power a good choice for governments in China?", Renewable and Sustainable Energy Reviews, vol. 73, p1218-1230

[11] Zhao, X. G. and Li, A. (2016): "A multi-objective sustainable location model for biomass power plants: Case of China", Energy, vol. 112, p1184-1193

[12] Klose, A. and Drexl, A. (2004): "Facility location models for distribution system design", European Journal of Operational Research, vol. 15, p413-417

[13] Yang, M.S, and Li, X. (2007): "Application of improved gravity method in location of logistics distribution center", Logistics Technology,vol. 6, p60-62

[14] Liu, H. W., Wang, C. L. Lun, M. H.and Chen, S. W. (2013): "Study on gravity model in optimization of logistics facilities location and its solution", Logistics Technology, vol. 7,p287-290

[15] Wang, P., Wang, X. Q. and Wang, M. B. (2005): "Logistics distribution center location of chain supermarket based on gravity method", Electronic Commerce, vol. 1, p43-44

[16] Contrerasa, I., Fernándezb, E., and Reineltc, G. (2012): "Minimizing the maximum travel time in a combined model of facility location and network design", Omega, vol. 6, p847-860

[17] Harkness, J. and ReVelle, C. (2003): "Facility location with increasing production costs", European Journal of Operational Research, vol. 1, p1-13

[18] Klamroth, K. and Weber, Planar (2001): "Location problems with line barriers", Optimization, vol. 49, p517-527

[19] Yi, J. M. (2013): "Logistics engineering", Publishing House of Electronics Industry, Beijing.

[20] Wei, J., Pi, A.T. and Zhang, J.H. (2012): "Research on the food distribution center location based on gravity method", Journal of Changsha University, vol. 2, p87-89

[21] Yuan, X. H., Lu, W. H. and Li, H. X. (2010): “Center-ofgravity fuzzy system and its probability representation theory", Journal of Liaoning Technical University (Natural Science), vol. 5, p795-798

[22] Taniguchi, E., Noritake, M., Yamada, T. and Izumitani, T. (1999): "Optimal size and location planning of public logistics terminals", Transportation Research, Vol. 35E, p207-222

[23] Hu, H.Z., Zhao, G. and Yang, H. N. (2010): "Fast algorithm to calculate generalized centroid of interval type-2 fuzzy set", Control and Decision, vol. 4, p637-640

[24] Zhao, L. (2012): "Research on the planning and site selection methods of straw power plants", M. S. Thesis, North China Electric Power University, March.

[25] Cheng, H. and Mou, R.F. (2014): "Location research of hazardous waste recycling center based on the improved gravity method", Journal of Transportation Engineering and Information, vol. 4, p108-113

[26] Li, L. H., Fu, Z., Hu, Z. D. and Zhou, H. P. (2012): , "Logistics nodes decision based on interval iterative genetic algorithm", Application Research of Computers, vol. 10, p3713-3716 